\title{
Arthroscopic side-to-side repair for complete radial posterior lateral meniscus root tears
}

\author{
Hongwu Zhuo, Qiang Chen, Fugui Zhu and Jian Li
}

\begin{abstract}
Background: The aim of this study was to determine the radiographic, second-look, and functional outcomes after arthroscopic side-to-side repair for complete radial posterior lateral meniscus root tears (PLMRTs).

Methods: Patients who underwent arthroscopic side-to-side repair for complete radial PLMRTs were identified. Clinical assessment consisted of symptoms (locking, catching, giving way and effusion), examinations of joint-line tenderness and McMurray test, and subjective scores of International Knee Documentation Committee (IKDC), Lysholm, and Tegner. In addition, postoperative MRI scan and second-look arthroscopy were performed to assess the healing status of the repaired meniscus.
\end{abstract}

Results: Twenty-nine patients met the inclusion criteria. The mean age was 25.41 years. The mean follow-up period was 26.68 months. During the follow-up, none of the patients had symptoms of meniscal retear, lateral joint-line tenderness or a positive McMurray test. The postoperative subjective scores of IKDC, Lysholm, and Tegner improved significantly compared to the preoperative values $(P=0.01)$. Postoperative MRI scan showed that $28 / 29(96.6 \%)$ patients achieved meniscus healing. Twenty-two patients underwent second-look arthroscopy, among whom 19 (86.4\%) patients showed complete meniscus healing and 3 (13.6\%) patients showed partial healing.

Conclusion: Arthroscopic side-to-side repair was a valuable surgical repair technique for complete radial PLMRTs, which leaded to significant improvements in both objective and subjective functional outcomes with a high rate of meniscus healing.

Level of evidence: Level IV, case series.

Keywords: Side-to-side, Repair, Radial, Meniscus root, Tear

\section{Background}

Posterior lateral meniscus root tears (PLMRTs) are defined as tears that occur within $9 \mathrm{~mm}$ of the posterior lateral meniscus insertion or as avulsions of the insertion [1]. According to Ahn's classification which is based on the arthroscopic findings, 4 types of PLMRTs are described: (1) radial tear with oblique flap, (2) longitudinal cleavage between the bony insertion and meniscal

\footnotetext{
* Correspondence: lijianla2008@foxmail.com

Fuzhou Second Hospital Affiliated to Xiamen University, No.47, Shang Teng Street, Cang Shan District, Fuzhou, China
}

femoral ligament (MFL) insertion, (3) acute T-type, and (4) chronic inner loss type [2]. Among these, radial tear is the most common type.

Previous studies have shown that complete radial PLMRTs disrupt the circumferential fibers of the meniscus and lead to loss of hoop stress, which results in an abnormal load sharing and unacceptable peak pressure in the tibiofemoral joint [1,3]. Thus, surgical repair should be attempted as much as possible. Currently, there are 2 common techniques of surgical repair described in the literature for complete radial PLMRTs:

(c) The Author(s). 2020 Open Access This article is licensed under a Creative Commons Attribution 4.0 International License, which permits use, sharing, adaptation, distribution and reproduction in any medium or format, as long as you give appropriate credit to the original author(s) and the source, provide a link to the Creative Commons licence, and indicate if changes were made. The images or other third party material in this article are included in the article's Creative Commons licence, unless indicated otherwise in a credit line to the material. If material is not included in the article's Creative Commons licence and your intended use is not permitted by statutory regulation or exceeds the permitted use, you will need to obtain permission directly from the copyright holder. To view a copy of this licence, visit http://creativecommons.org/licenses/by/4.0/ The Creative Commons Public Domain Dedication waiver (http://creativecommons.org/publicdomain/zero/1.0/) applies to the data made available in this article, unless otherwise stated in a credit line to the data. 
transtibial pull-out technique and side-to-side repair technique [4-10]. Transtibial pull-out technique has been reported to successfully restore the meniscal functions by securing the meniscus to its original anatomic insertion site on the tibia $[4,5]$. However, when the root fragment of the meniscus is large enough, side-to-side repair technique is theoretically biomechanically superior as it repairs the meniscus anatomically without changing its native physiologic properties [6-10].

To our best knowledge, there is still limited data in the literation regarding the clinical outcomes after arthroscopic side-to-side repair for complete radial PLMRTs. Therefore, the aim of this present study was to assess the radiographic, second-look, and functional outcomes after arthroscopic side-to-side repair for complete radial PLMRTs. We hypothesized that this surgical procedure would result in significant improvements in both objective and subjective functional outcomes with a high rate of meniscus healing.

\section{Methods}

\section{Study design}

From March 2014 to March 2017, the medical records of patients who underwent arthroscopic surgery for PLMRTs at our institution were identified. The inclusion criteria were (1) patients who were diagnosed with complete radial PLMRTs and underwent arthroscopic side-to-side repair, and (2) patients with a minimum 2-year follow-up. The exclusion criteria were (1) age older than 60 years, (2) significant osteoarthritis of the joint (Kellgren-Lawrence grade III or IV), or (3) previous surgery of the same knee. As complete radial PLMRTs occurred frequently associated with anterior cruciate ligament (ACL) injury, so concomitant ACL injury was not an exclusion criterion for this study.

A total of 122 patients (122 knees) who underwent arthroscopic surgery for PLMRTs at our institution were identified (Fig. 1). Of these, 37 patients were diagnosed with complete radial PLMRTs and all these patients underwent arthroscopic side-to-side repair. Among them, one patient was older than 60 years, one patient had significant knee osteoarthritis, one patient had previous surgery for tibial plateau fracture, three patients were lost to follow-up with a follow-up period less than 2 years, and two patients had incomplete clinical functional assessments. Therefor, we studied the remaining 29 patients (29 knees).

This study received approval from our institutional review board. All patients provided signed informed consent to allow their clinical and radiological data to be used for research programs.

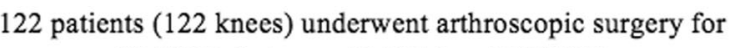

37 patients were diagnosed with complete radial PLMRTs and underwent arthroscopic side-to-side repair

Excluded $(\mathrm{n}=8)$

- 1 patient was older than 60 years

- 1 patient had significant knee osteoarthritis

- 1 patient had previous surgery of the ipsilateral limb

- 3 patients were lost to follow-up

- 2 patients had incomplete clinical functional assessment

29 patients were enrolled in this study

Fig. 1 Flow chart of this study 


\section{Surgical technique}

All surgeries were performed under general anesthesia. The patients were placed in a supine position. An arthroscopic evaluation was performed using two standard anterior knee arthroscopy portals. If the ACL was torn, the lateral meniscus was addressed before ligament reconstruction. The knee was placed in the figure-of- 4 position. The torn edge of the meniscus was refreshed with a motorized shaver (Fig. 2a). A suture hook loaded with a No. 2 polydioxanone (PDS; Ethicon, Somerville, NJ) suture was introduced through the anterolateral portal and pierced the outer part of the meniscus downward approximately $5 \mathrm{~mm}$ away from the torn edge. Then, a suture hook loaded with a lasso loop was introduced through the anteromedial portal and pierced the inner part of the meniscus downward to bring the inferior end of the PDS suture through the inner part of the meniscus upward (Fig. 2b). Next, both of the two free ends of the PDS suture were retrieved and tied with four to five simple knots using the arthroscopic knot pusher (Fig. 2c).

The same procedure was repeated and it required usually 2 or 3 stitches to form a firm repair (Fig. 2d).

\section{Postoperative rehabilitation}

Postoperatively, the leg was immobilized with a knee brace in full extension. Quadricep-strengthening exercises were started on the second day. Passive knee flexion was started at 2 weeks postoperatively, while active knee flexion was started at 4 weeks postoperatively. Partial weight bearing was allowed at 6 weeks postoperatively and full weight bearing was allowed at 8 weeks postoperatively. Normal activities were permitted at 6 months postoperatively.

\section{Assessment}

Demographic data were collected from the database, including age, sex, side of injury, time from injury to surgery, and concomitant surgical procedures. The patients were assessed preoperatively; at 1, 3, 12, and 24 months postoperatively; and at the final follow-up.

The functional outcomes were assessed by both objective and subjective measures. These measures included (1) the symptoms of meniscus retear, such as locking, catching, giving way and effusion; (2) examinations of joint-line tenderness and McMurray test; and (3) International Knee Documentation Committee
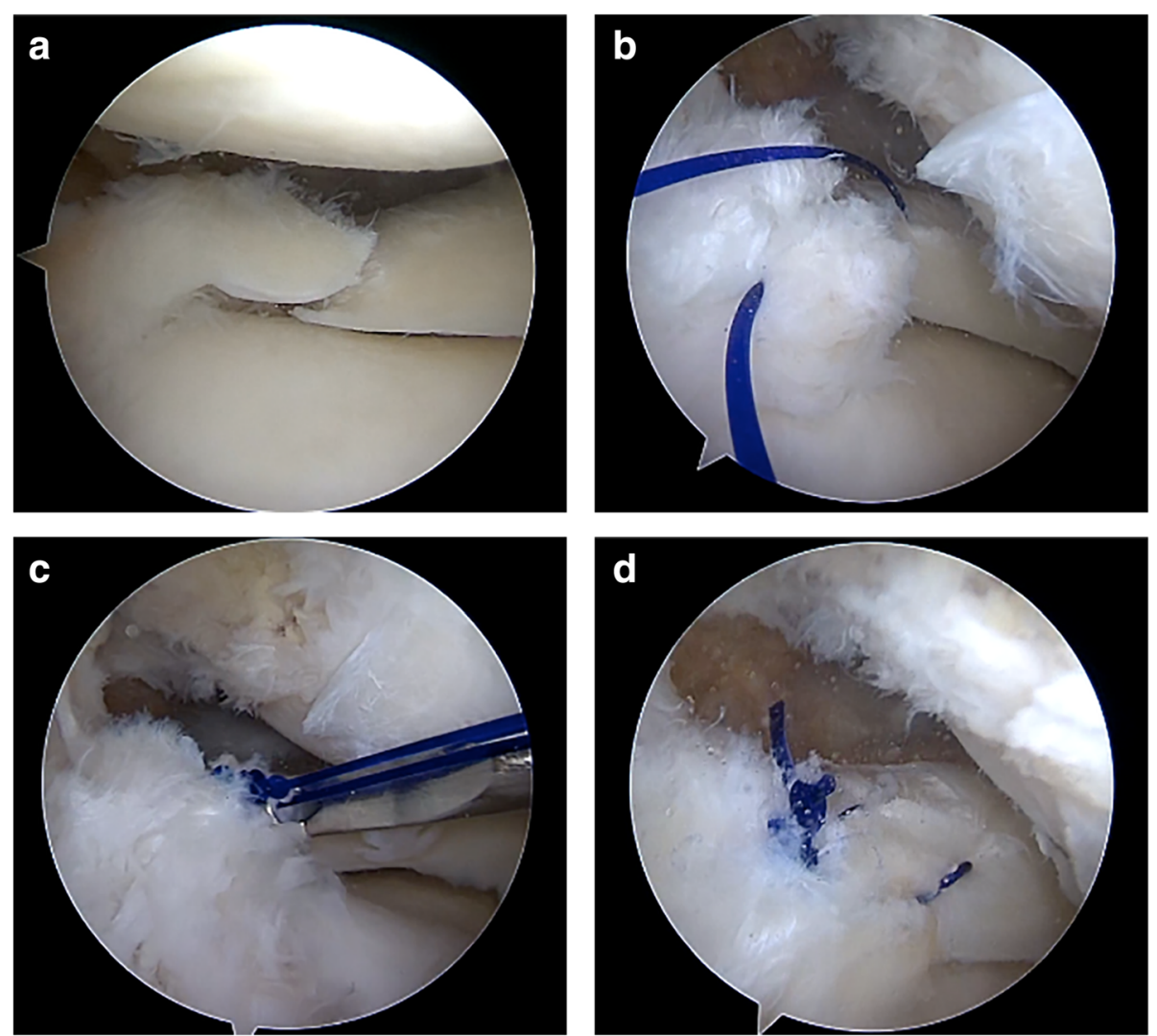

Fig. 2 Arthroscopic side-to-side repair for complete radial PLMRTs (left knee). a A complete radial PLMRT; b A PDS suture was passed through both sides of the torn meniscus; $\mathbf{c}$ The two ends of the PDS suture were tied using a knot pusher; $\mathbf{d}$ A total of 2 stitches were required to create a stable repair 
(IKDC) score, Lysholm score, and Tegner score. According to Barrett's criteria, a repaired meniscus was considered clinical healing if there was no joint line tenderness, no effusion and a negative McMurray's test [11].

At the final follow-up, MRI scan (3.0-T MR System, Signa Excite, GE Medical Systems, Waukesha, Wisconsin, USA) was obtained for assessment of the healing status of the repaired meniscus. A repaired meniscus was considered failure of healing if one of following MRI signs was present: (1) "ghost sign", the absence of an identifiable meniscus on the sagittal sequence or high signal replacing the normal dark meniscus [12]; (2) meniscal extrusion, a meniscal sagittal displacement of $>3 \mathrm{~mm}$ at the level of the medial collateral ligament [13]; and (3) abnormal hyperintensity signal, which extended to the articular surface of the meniscus root [14].

For the patients who wanted to remove the implant for ACL reconstruction and agreed to undergo secondlook arthroscopy, the healing status of the repaired meniscus was assessed using an arthroscopic probe and classified according to Horibe's criteria [15]. If there was no visible surface defect with complete synovial coverage, it was defined as complete healing. If there was a small defect with synovial coverage over more than half of the torn area, it was defined as partial healing. If there was a large defect with synovial coverage over less than half of the torn area, it was defined as failure of healing.

\section{Statistical analysis}

All statistical analyses were performed using SPSS software (IBM-SPSS statistics 22.0; New York, USA). Continuous variables were presented as the mean and standard deviation. A paired-samples $t$ test was used to determine the differences between preoperative and postoperative quantitative variables. The significance level was set at 0.05 .

\section{Results}

\section{Demographic data}

A total of 29 patients met the inclusion criteria and were enrolled in this study. There were 21 males and 8 females with a mean age of $25.41 \pm 6.61$ years (range, 1739 years). The mean follow-up period was $26.68 \pm 2.91$ months (range, 24-36 months). The demographic data of the patients are summarized in Table 1.

\section{Functional outcomes}

During the follow-up, none of the patients complained of locking, catching, giving way or effusion. None of the patients had lateral joint-line tenderness or a positive McMurray test. Thus, the repaired meniscus was considered having a $100 \%$ clinical success rate. At the final follow-up, the subjective scores of IKDC, Lysholm, and
Table 1 Demographic data of the patients

\begin{tabular}{ll}
\hline Variable & Value \\
\hline Patients, $\mathrm{n}$ & 29 \\
Age, years & $25.41 \pm 6.61$ \\
Sex, male/female & $21 / 8$ \\
Side, right/left & $16 / 13$ \\
Time from injury to surgery, months & $3.38 \pm 4.17$ \\
Concomitant surgical procedures, $\mathrm{n}$ & \\
$\quad$ Anterior cruciate ligament reconstruction & 26 \\
$\quad$ Partial or total meniscectomy of medial meniscus & 14 \\
$\quad$ Debridement for cartilage damage & 3 \\
Follow-up period, months & $26.68 \pm 2.91$
\end{tabular}

The data are shown as mean \pm standard deviation or $n$

Tegner improved significantly compared to the preoperative values (Table 2).

\section{Radiographic and second-look outcomes}

The postoperative MRI showed that 28 (96.6\%) patients achieved complete healing and 1 patient achieved failure of healing with an abnormal hyperintensity signal in the repair site. Twenty-two patients underwent second-look arthroscopy at mean 13.0 \pm 1.31 months (range, 11-16 months) postoperatively. On the second-look arthroscopy, 19 (86.4\%) patients showed complete meniscus healing (Fig. 3) and 3 (13.6\%) patients showed partial healing. No failure of healing was detected among these 22 patients.

\section{Discussion}

The most important finding in this present study was that the subjective scores of IKDC, Lysholm, and Tegner after arthroscopic side-to-side repair for complete radial PLMRTs got significant improvement with a clinical success rate of $100 \%$ at a mean follow-up of 26.68 months. Moreover, $96.6 \%$ of patients showed meniscus healing on the postoperative MRI. Twenty-two patients underwent second-look arthroscopy and 19 patients showed complete meniscus healing.

\section{Biomechanical consequences of complete radial PLMRTs}

The primary biomechanical function of meniscus is to convert the tibiofemoral axial load into hoop stress during both knee extension and deep flexion [16]. Complete radial PLMRTs disrupt the continuity of the circumferential fibers and lead to loss of hoop stress, causing overload of the lateral compartment and early degenerative changes $[1,3]$. A recent biomechanical study by Schillhammer showed that PLMRTs resulted in a significantly increased peak contact pressure (49\%) and decreased tibiofemoral contact area (33\%) [17]. The posterior lateral meniscus root is also an important secondary 
Table 2 Comparison of the preoperative and postoperative functional outcomes

\begin{tabular}{llllllll}
\hline Variables & Preoperative & $\begin{array}{l}1 \text { month } \\
\text { postoperatively }\end{array}$ & $\begin{array}{l}3 \text { month } \\
\text { postoperatively }\end{array}$ & $\begin{array}{l}12 \text { month } \\
\text { postoperatively }\end{array}$ & $\begin{array}{l}24 \text { month } \\
\text { postoperatively }\end{array}$ & $\begin{array}{l}\text { Final } \\
\text { follow-up }\end{array}$ & $\begin{array}{l}P \text { Value (preoperative vs final } \\
\text { follow-up) }\end{array}$ \\
\hline $\begin{array}{l}\text { IKDC } \\
\text { score }\end{array}$ & $53.4 \pm 5.32$ & $26.4 \pm 2.32$ & $47.9 \pm 3.74$ & $84.0 \pm 3.09$ & $91.4 \pm 2.72$ & $92.1 \pm 2.64 .01$ \\
$\begin{array}{l}\text { Lysholm } \\
\text { score }\end{array}$ & $56.3 \pm 4.59$ & $49.2 \pm 4.44$ & $88.0 \pm 2.10$ & $94.9 \pm 2.59$ & $95.1 \pm 2.85$ & $95.1 \pm 2.85 .01$ \\
$\begin{array}{l}\text { Tegner } \\
\text { score }\end{array}$ & $2.41 \pm 0.56$ & $0.17 \pm 0.38$ & $2.46 \pm 0.67$ & $5.27 \pm 0.75$ & $5.41 \pm 0.66$ & $5.55 \pm 0.63 .01$
\end{tabular}

The data are shown as mean \pm standard deviation

restraint to the rotational laxity of the knee joint. To date, several studies have shown that PLMRTs further destabilize the rotational stability of the ACL-deficient knee under a simulated pivot-shift loading [18, 19]. Overall, complete radial PLMRTs have severe biomechanical consequences and are functionally equivalent to a total meniscectomy.

\section{Surgical repair of complete radial PLMRTs}

Arthroscopic transtibial pull-out technique and side-toside repair technique are the 2 most common techniques of surgical repair for complete radial PLMRTs [4-10]. The former involves a bone tunnel running from the anteromedial aspect of the tibia to the anatomic attachment site of the lateral meniscal root on the tibia. Sutures are then passed through the meniscal root and through the tunnel and secured over the anterior tibia. However, the theoretical disadvantages of this technique include (1) need for a bone tunnel which might interfere with concomitant ligament reconstruction, (2) need for distal fixation which places the sutures at risk for failure, and (3) if the root fragment is large, that the outer part of the meniscus is secured to the original insertion site will cause an increased meniscal tension [20]. In

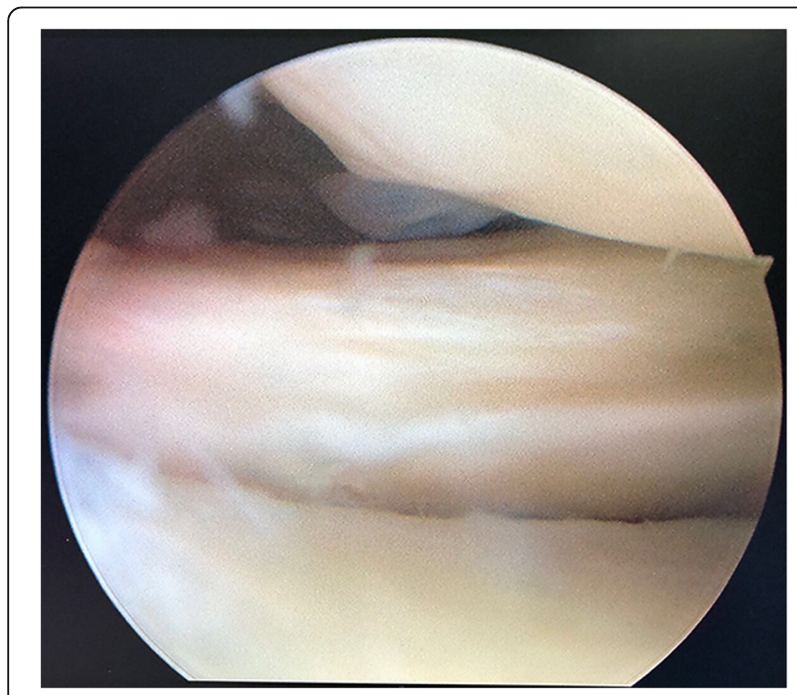

Fig. 3 Complete meniscal healing on the second-look arthroscopy contrast, side-to-side repair belongs to anatomic repair that does not change the native anatomic and physiologic properties of the meniscus.

Recently, posterior lateral meniscus root fixation using suture anchors has also been described [21]. The main concerns about this technique include anchor pullout with subsequent failure of fixation, and technical difficulty [22].

\section{Clinical outcomes after arthroscopic side-to-side repair for complete radial PLMRTs}

To date, the studies regarding the clinical outcomes after arthroscopic side-to-side repair for treatment of complete radial PLMRTs remain limited. Ahn reported a cohort of 27 patients who underwent arthroscopic sideto-side repair for complete radial PLMRTs [6]. The clinical healing rate of the repaired meniscus was up to $100 \%$ at 1 year postoperatively. Eight of the nine patients who underwent second-look arthroscopy showed complete meniscus healing. Anderson retrospectively reviewed 8 patients who underwent arthroscopic sideto-side repair for complete radial PLMRTs [7]. The mean IKDC, Lysholm, and Tegner scores improved significantly at a mean follow-up of 70.5 months. In another study, Song analyzed a small sample of 15 patients with complete radial PLMRTs who underwent arthroscopic side-to-side repair using a Fast-Fix device [8]. At a mean follow-up of 24 months, all the patients showed clinical healing, and $86.6 \%$ of the patients showed meniscus healing on the second-look arthroscopy. Similar to these studies, this present study also showed that arthroscopic side-to-side repair could significantly improve both objective and subjective functional outcomes with a high rate of meniscus healing in patients with complete radial PLMRTs.

This study has several limitations. First, this study was a retrospective study with all the inherent limitations of a retrospective study. Second, this study included a limited number of patients. Third, the period of the follow-up was 2 years but still relatively short, and longer-term evaluations are required to evaluate long-term clinical outcomes. Fourth, this study did not involve any control group. 


\section{Conclusions}

Arthroscopic side-to-side repair was a valuable surgical repair technique for complete radial PLMRTs. This surgical procedure leaded to significant improvements in both objective and subjective functional outcomes with a high rate of meniscus healing.

\section{Abbreviations}

ACL: Anterior cruciate ligament; IKDC: International Knee Documentation Committee; MFL: Meniscal femoral ligament; PLMRTs: Posterior lateral meniscus root tears

\section{Acknowledgements}

Not applicable.

\section{Authors' contributions}

$\mathrm{HZ}$ analysed and interpreted the patient data. QC and FZ were major contributors to manuscript writing. JL performed all the surgeries. All authors read and approved the final manuscript.

\section{Funding}

None.

\section{Availability of data and materials}

The raw data are available from the corresponding author upon reasonable request.

\section{Ethics approval and consent to participate}

All patients provided signed informed consent to allow their clinical and radiologic data to be used for research programmes. For the patient (No.8, 15 year-old), a written informed consent was obtained from her father. The name of the Board: Institutional Review Board of Fuzhou Second Hospital of Xiamen University. Approval number is INR 10020190108.

\section{Consent for publication}

Not applicable.

\section{Competing interests}

The authors declare that they have no competing interests.

Received: 10 October 2019 Accepted: 21 February 2020

Published online: 28 February 2020

\section{References}

1. Bhatia S, LaPrade CM, Ellman MB, et al. Meniscal root tears: significance, diagnosis, and treatment. Am J Sports Med. 2014;42(12):3016-30. https://doi. org/10.1177/0363546514524162.

2. Ahn JH, Lee YS, Chang JY, et al. Arthroscopic all inside repair of the lateral meniscus root tear. Knee. 2009;16(1):77-80. https://doi.org/10.1016/j.knee. 2008.07.008.

3. Brody JM, Lin HM, Hulstyn MJ, et al. Lateral meniscus root tear and meniscus extrusion with anterior cruciate ligament tear. Radiology. 2006; 239(3):805-10

4. Cerminara AJ, LaPrade CM, Smith SD, et al. Biomechanical evaluation of a transtibial pull-out meniscal root repair: challenging the bungee effect. Am J Sports Med. 2014;42(12):2988-95. https://doi.org/10.1177/ 0363546514549447.

5. LaPrade RF, Matheny LM, Moulton SG, et al. Posterior meniscal root repairs: outcomes of an anatomic Transtibial pull-out technique. Am J Sports Med. 2017:45(4):884-91. https://doi.org/10.1177/0363546516673996.

6. Ahn JH, Lee YS, Yoo JC, et al. Results of arthroscopic all-inside repair for lateral meniscus root tear in patients undergoing concomitant anterior cruciate ligament reconstruction. Arthroscopy. 2010;26(1):67-75. https://doi. org/10.1016/j.arthro.2009.07.007

7. Anderson L, Watts $M$, Shapter $O$, et al. Repair of radial tears and posterior horn detachments of the lateral meniscus: minimum 2-year follow-up. Arthroscopy. 2010;26(12):1625-32. https://doi.org/10.1016/j. arthro.2010.07.020.
8. Song HS, Bae TY, Park BY, et al. Repair of a radial tear in the posterior horn of the lateral meniscus. Knee. 2014;21(6):1185-90. https://doi.org/10.1016/j. knee.2014.07.018.

9. Ouanezar $\mathrm{H}$, Thaunat M, Saithna A, et al. Suture repair of full radial posterior lateral meniscus tears using a central midline portal. Arthrosc Tech. 2017; 6(5):e1801-6. https://doi.org/10.1016/j.eats.2017.06.054.

10. Soejima T, Tabuchi $K$, Noguchi $K$, et al. An all-inside repair for full radial posterior lateral meniscus tears. Arthrosc Tech. 2016;5(1):e133-8. https://doi. org/10.1016/j.eats.2015.10.013.

11. Barrett $G R$, Field MH, Treacy SH, et al. Clinical results of meniscus repair in patients 40 years and older. Arthroscopy. 1998;14(8):824-9.

12. Kim SB, Ha JK, Lee SW, et al. Medial meniscus root tear refixation: comparison of clinical, radiologic, and arthroscopic findings with medial meniscectomy. Arthroscopy. 2011;27(3):346-54. https://doi.org/10.1016/j. arthro.2010.08.005

13. Choi CJ, Choi YJ, Lee JJ, et al. Magnetic resonance imaging evidence of meniscal extrusion in medial meniscus posterior root tear. Arthroscopy. 2010;26(12):1602-6. https://doi.org/10.1016/j.arthro.2010.05.004.

14. Lim PS, Schweitzer ME, Bhatia M, et al. Repeat tear of postoperative meniscus: potential MR imaging signs. Radiology. 1999;210(1):183-8.

15. Horibe S, Shino K, Maeda A, et al. Results of isolated meniscal repair evaluated by second-look arthroscopy. Arthroscopy. 1996:12(2):150-5.

16. Papalia R, Vasta S, Franceschi F, et al. Meniscal root tears: from basic science to ultimate surgery. Br Med Bull. 2013;106:91-115. https://doi.org/10.1093/ $\mathrm{bmb} / \mathrm{ldt002}$

17. Schillhammer CK, Werner FW, Scuderi MG, et al. Repair of lateral meniscus posterior horn detachment lesions: a biomechanical evaluation. Am J Sports Med. 2012:40(11):2604-9. https://doi.org/10.1177/0363546512458574.

18. MusahI V, Citak M, O'Loughlin PF, et al. The effect of medial versus lateral meniscectomy on the stability of the anterior cruciate ligament-deficient knee. Am J Sports Med. 2010;38(8):1591-7. https://doi.org/10.1177/ 0363546510364402.

19. Shybut TB, Vega CE, Haddad J, et al. Effect of lateral meniscal root tear on the stability of the anterior cruciate ligament-deficient knee. Am J Sports Med. 2015:43(4):905-11. https://doi.org/10.1177/0363546514563910.

20. Koenig JH, Ranawat AS, Umans HR, et al. Meniscal root tears: diagnosis and treatment. Arthroscopy. 2009;25(9):1025-32. https://doi.org/10.1016/j.arthro. 2009.03.015.

21. Cuéllar A, Cuéllar A, Sánchez A, et al. Posterior lateral meniscus root reattachment with suture anchors: an arthroscopic technique. Arthrosc Tech. 2017;6(5):e1919-25. https://doi.org/10.1016/j.eats.2017.07.011.

22. Kim JH, Chung JH, Lee $\mathrm{DH}$, et al. Arthroscopic suture anchor repair versus pullout suture repair in posterior root tear of the medial meniscus: a prospective comparison study. Arthroscopy. 2011;27(12):1644-53. https:// doi.org/10.1016/j.arthro.2011.06.033.

\section{Publisher's Note}

Springer Nature remains neutral with regard to jurisdictional claims in published maps and institutional affiliations.

Ready to submit your research? Choose BMC and benefit from:

- fast, convenient online submission

- thorough peer review by experienced researchers in your field

- rapid publication on acceptance

- support for research data, including large and complex data types

- gold Open Access which fosters wider collaboration and increased citations

- maximum visibility for your research: over $100 \mathrm{M}$ website views per year

At BMC, research is always in progress.

Learn more biomedcentral.com/submissions 